\author{
Research Article
}

\title{
Catalytic Pyrolysis and a Pyrolysis Kinetic Study of Shredded Printed Circuit Board for Fuel Recovery
}

\author{
Chee Hoe Ng$^{1}$, Ali Salmiaton ${ }^{*}$, Hashim Hizam ${ }^{2}$ \\ ${ }^{1}$ Department of Chemical and Environmental Engineering, Faculty of Engineering, Universiti \\ Putra Malaysia, 43400 UPM Serdang, Selangor, Malaysia. \\ ${ }_{2}^{2}$ Department of Electrical and Electronic Engineering, Faculty of Engineering, Universiti Putra \\ Malaysia, 43400 UPM Serdang, Selangor, Malaysia.
}

Received: 23rd July 2014; Revised: 14th August 2014; Accepted: 14th August 2014

Abstract

Scrap printed circuit boards (PCBs) are the most abundant wastes that can be found in the landfills in Malaysia and this disposal certainly poses serious detrimental to the environment. This research aims to investigate optimum temperature for pyrolyzing waste PCBs, find out the best catalyst to be used in accelerating PCBs' pyrolysis, select suitable ratio of catalyst to PCBs for higher oil yield and examine kinetics pyrolysis of the waste PCBs' decomposition. Operating temperatures ranged from 200 to 350 ${ }^{\circ} \mathrm{C}$ of PCB's pyrolysis were conducted with the optimum temperature obtained was $275{ }^{\circ} \mathrm{C}$. Fluid catalytic cracking (FCC) catalyst, zeolite socony mobil-5 (ZSM-5), H-Y-type zeolite and dolomite were used to accelerate PCB's pyrolysis at $275^{\circ} \mathrm{C}$ and FCC was identified as the best catalyst to be used. Different ratios of FCC to waste PCBs such as 10:90, 20:80, 30:70, 40:60 and 50:50 were applied in the pyrolysis at $275{ }^{\circ} \mathrm{C}$ and ratio of $10: 90$ was selected as the suitable ratio to be utilized for maximum yield. The kinetic study was done through thermogravimetric analysis on waste PCBs under various heating rates and different particle sizes. The GC-MS analysis revealed that compounds detected in the pyrooil have the potential to be used as fuel. (C) 2014 BCREC UNDIP. All rights reserved

Keywords: Scrap Printed Circuit Boards; Pyrolysis; Pyro-Oil; Kinetics

How to Cite: Ng, C.H., Salmiaton, A., Hizam, H. (2014). Catalytic Pyrolysis and a Pyrolysis Kinetic Study of Shredded Printed Circuit Board for Fuel Recovery. Bulletin of Chemical Reaction Engineering \& Catalysis, 9 (3): 224-240. (doi:10.9767/bcrec.9.3.7148.224-240)

Permalink/DOI: http://dx.doi.org/10.9767/bcrec.9.3.7148.224-240

\section{Introduction}

Undoubtedly, the fastest growing manufacturing fields in Malaysia is none other than electrical and electronics' production. Generally, most of the invented electrical and electronic appliances will contain printed circuit boards and these printed circuit board (PCB) wastes are very difficult to be reused and recy-

${ }^{*}$ Corresponding Author.

Email: mie@upm.edu.my (A. Salmiaton)

Tel: +00-603-89466297; Fax: +00-603-86567120 cled due to its high content of metals and polymers. Typically, PCBs are the mixtures of woven glass reinforced resin and multiple types of metals. From Figure 1, it can be concluded that e-waste generation in Malaysia is still in the continual rise till today and this increment rate should become our major concern. In general, the components of waste PCBs can be divided into metallic fractions and non-metallic fractions. Besides that, PCBs contain significant quantities of metals such as copper (16\%), solder (4\%), iron and ferrite (3\%), and nickel (2\%) [1]. 
Proper management of waste PCBs disposal is gaining momentum across the world because waste PCBs are difficult to be recycled due to its diverse mixture of glass fibers, metals and organic materials. Improper management of PCBs waste disposal will eventually lead to pollution and health concerns. The conventional low cost management of waste PCBs is land filling and metal recycling whereas incineration is considered as the high cost management of waste PCBs. Indiscriminate combustion of epoxy resins in the waste PCBs via incineration will eventually release many carcinogenic gases such as furans, dioxins, or persistent organic pollutants (POPs) [3]. These potent gases cause serious damage to the human's nervous and immune system due to the excessive inhalation. The quantity of such gases being released into the atmosphere cannot be compromised as the minimum allowable gas emission has been enforced by the Department of Environment in the recent years.

Both physical recycling methods and chemical recycling methods have been practiced for decades and apparently there are no contemporary technologies available to replace both methods effectively. The discussions are made regarding the advantages and disadvantages of adopting both physical and chemical methods. Physical recycling methods of non-metallic fractions are adopted after the metallic fractions and non-metallic fractions have been segregated from PCBs waste by using mechanical processing [4]. Several mechanical processing used for segregating the metallic fractions and non-metallic fractions from PCBs waste are grinding, multi-crushing, magnetic separation, density-based separation, electric conductivitybased separation, corona electrostatic separation and shape separation [5]. Metals of waste PCBs can be stripped off from the plates when the grinding and crushing are carried out. But

Quantity of e-waste Generated in Year 2006-2009

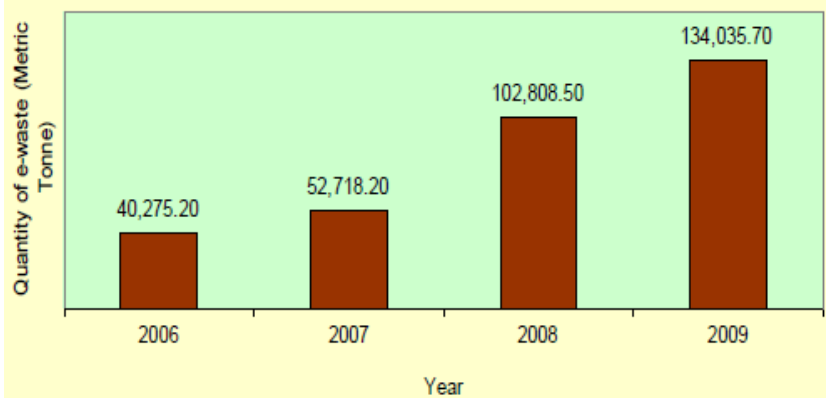

Figure 1. Quantity of e-waste generated in year 2006 to 2009 [2] the drawback of using mechanical processing is the dust and hazardous gas production during the crushing or grinding due to strength and firmness of waste PCBs. Hydrometallurgical is considered as one of the physical recycling method and it is used to recover valuable metals from waste PCBs [6]. However, a lot of liquid waste and sludge are produced in the hydrometallurgical and these wastes need to be disposed of carefully.

There are many uses for non-metallic fraction of waste PCBs after the physical recycling processing is carried out. The powder formed after crushing can be used as the paving material or plastic filling materials. Besides that, the non-metallic fractions of waste PCBs have to be thermally stable during the injection molding or compression molding [7]. In addition, the components such as thermosetting resins, ceramics and glass fiber deposited in the non-metallic fractions from PCBs waste can be used as filler for different resin matrix composites [8]. In fact, most researchers across the globe prefer to recycle the non-metallic fractions of waste PCBs as the fillers for thermosetting resin composites when the physical recycling methods are selected [9].

There are several advantages of adopting physical recycling methods because physical recycling methods are relatively simple, environmentally sound and convenient in handling the non-metallic fractions from waste PCBs. Furthermore, the investment on equipment is quite low and energy cost is relatively cheaper and at the same time, the potential application of products made from the non-metallic fractions of PCBs waste is capitalized [10]. There are still some drawbacks faced in adopting physical recycling methods of the non-metallic fractions and the drawbacks are the difficulties of getting a clean segregation between metallic fractions and non-metallic fractions from PCBs waste, finding suitable way to enhance the compatibility between non-metallic fractions and the matrix materials, considering the good solution for preventing the hazardous substances from leaching out of the products to the least extent, etc. [11]. In short, the conventional physical recycling technologies cannot meet the present requirements of industry because of the environmental contamination, high cost and low efficiency. It is vital to develop a new clean technology for recycling valuable resources. Besides that, the limitation of using mechanical and hydrometallurgical method is the brominated epoxy resin which is left untreated and remains in the waste PCBs. The untreated brominated epoxy requires fur- 
ther treatment and disposal [12].

Chemical recycling refers to the decomposition of the waste polymers into monomers or other useful chemical products through chemical reactions. Chemical recycling methods available to date are pyrolysis, gasification, depolymerization process by using supercritical fluids and hydrogenolytic degradation [13]. Pyrolysis can be considered as an alternative method of recycling waste PCBs because during the pyrolysis, the organic materials are decomposed into low molecular weight products in liquid and gases phases. The pyro-oil produced can be used as fuel or chemical feedstock for the downstream processing industries while the inorganic materials such as metal elements and glass fibers are remained in the solid residue after pyrolysis. The latter can be recycled for other valuable applications such as manufacturing of resin matrix composites [5].

Hall and his colleagues [14] carried out the pyrolysis of PCBs waste from waste computers, televisions and mobile phones in a fixed bed reactor with the aim of segregating and recovering the organic and metallic materials. The efficiency of PCBs waste pyrolysis can be increased with addition of proper catalysts such as zeolite-based catalyst. Hall and his colleagues used a fluidized catalytic cracking (FCC) catalyst to pyrolyse e-waste plastics. In their work, they found out that toxic brominated compound in the PCBs waste could be removed with the use of zeolite-based waste FCC catalyst [14]. The investigation was carried out using fixed bed reactor and the pyrolysis products were characterized using Fouriertransform infrared spectroscopy, ion and gas chromatography. Cui and her colleagues reported that gases emitted from pyrolysis of waste PCBs are generally consisted of $\mathrm{CO}_{2}, \mathrm{CO}$, $\mathrm{C}_{1}-\mathrm{C}_{4}$ alkanes and other light hydrocarbons [15]. These gases can be used as the combustible gas or feedstock for chemical syntheses such as methanol, pure naphtha production, Fischer-Tropsh syntheses and oxo-synthesis processes. Pyro-oil produced can be used as fuel oil or feedstock as it contains huge amount of phenol and phenol derivatives. The chars remained after pyrolysis can be used for making of composites after metal extraction has been carried out [16].

In this study, a pyrolysis of PCBs waste was carried out with the presence of catalysts after the optimum operating temperature had been identified. Catalysts such as fluidized catalytic cracking (FCC) catalyst, zeolite socony mobil-5 (ZSM-5), H-Y type zeolite and dolomite were used to accelerate the pyrolysis of PCBs waste in the fixed bed lab-scale reactor. Effectiveness of each catalyst on the PCBs waste pyrolysis was investigated. The best ratio of catalyst to waste PCBs was determined after the selection of best catalyst had been done. All products such as gases, oils and solid residue formed during the pyrolysis were identified and examined using analytical equipment such as gas chromatography-mass spectrometry (GC-MS), Fourier transform infrared spectroscopy (FTIR) and inductively coupled plasma mass spectrometry (ICP-MS). Besides that, thermal decomposition pathways of waste PCBs on the common thermogravimetric analyzer (TGA) were also examined. The effects of particle size and heating rate on the overall reaction rate were assessed. The kinetic behaviors of waste PCBs were discussed using distributed activation energy model with the activation energy and order of reaction were determined via calculation.

\section{Materials and Methods}

\subsection{Material Preparation}

Materials used in the research were shredded PCBs obtained from a local recycling company in Malaysia. Nitrogen gas (99.8\%) as a carrier gas during pyrolysis, was purchased from Southern Industrial Gas Sdn Bhd., Nilai, Negeri Sembilan. Catalysts used in the pyrolysis are FCC catalyst, ZSM-5 zeolite, H-Y-type zeolite and dolomite. All catalysts used in the pyrolysis were supplied by Qingdao Wish Chemicals Co., Ltd., China whereas dolomite was supplied by Northern Dolomite Sdn. Bhd., Perlis. The quantity of waste PCBs used was 30 $\pm 5 \mathrm{~g}$ and the quantities of catalysts used were varied with the ratio of catalyst to waste PCBs. Dichloromethane (DCM) was used as solvent to collect oil from the flue gas coming out from the fluidized bed reactor and it was purchased from R\&M Chemicals, Selangor. Ice bath was used to provide homogeneous temperature for oil collection by dichloromethane. Gravels of size between $3 \mathrm{~mm}$ and $5 \mathrm{~mm}$ were used as a bed for the pyrolysis in the fluidized bed lab-scale reactor.

\subsection{Characterization of Waste PCBs}

\subsubsection{Proximate Analysis}

Proximate analysis of the waste PCBs was done using thermogravimetric analyzer (model Mettler Toledo, TGA/SDTA851, USA). In this analysis, about $8.35 \mathrm{mg}$ of waste PCBs was heated in an alumina crucible at $10{ }^{\circ} \mathrm{C} / \mathrm{min}$ from room temperature to $600{ }^{\circ} \mathrm{C}$ under $\mathrm{N}_{2}$ gas 
flow of $10 \mathrm{ml} / \mathrm{min}$. Air flow of $10 \mathrm{ml} / \mathrm{min}$ was introduced at $600{ }^{\circ} \mathrm{C}$ and the waste PCBs were continuously heated to $900{ }^{\circ} \mathrm{C}$ at the heating rate of $10{ }^{\circ} \mathrm{C} / \mathrm{min}$ to determine the fixed carbon content in waste PCBs. The remaining residue after combustion was considered as the ash content of waste PCBs.

\subsubsection{Metal Analysis}

Metal analysis in the waste PCBs and solid residue was conducted using inductively coupled plasma mass spectrometry (model Perkin Elmer, ICP Optima 7300DV/07709022401, USA).

\subsection{Thermal Decomposition and Kinetics Analysis}

Thermal decomposition and kinetic analysis were performed using thermogravimetric analyzer (TGA, model Mettler Toledo, TGA/SDTA851, USA). In recent years, many reports on kinetic studies of waste PCBs have been done and these literature studies were carried out using thermo balance equipment [17-19].

The overall thermal decomposition of waste PCBs can be written in Arrhenius equation. It is expressed as:

$$
\frac{d X}{d t}=\operatorname{Aexp}\left(\frac{-E_{a}}{R T}\right) f(x)
$$

where $k$ is the rate constant, $A$ is the preexponential factor, $E_{a}$ is the activation energy and $T$ is the reaction temperature. A function of conversion independent of temperature, $f(X)$, is expressed as:

$$
f(X)=(1-X)^{n}
$$

The decomposition kinetics of waste PCBs was evaluated using Friedman technique [20]. Friedman provides the following kinetic studies based on basic Arrhenius equation:

$$
\ln \left(\frac{d X}{d t}\right)=\ln (Z)+n \ln (1-X)-\frac{E_{a}}{R T}
$$

where $X$ is the conversion at time $t, T$ is the absolute temperature $(\mathrm{K})$ and $R$ is the value of gas constant $(8.31 \mathrm{~J} / \mathrm{mol} / \mathrm{K})$. The plot of $\ln (d X /$ $d t)$ vs. $1 / T$ should be linear with the slope of $E_{a} /$ $R$ from which $E_{a}$ can be obtained. Value of $\mathrm{n}$ is

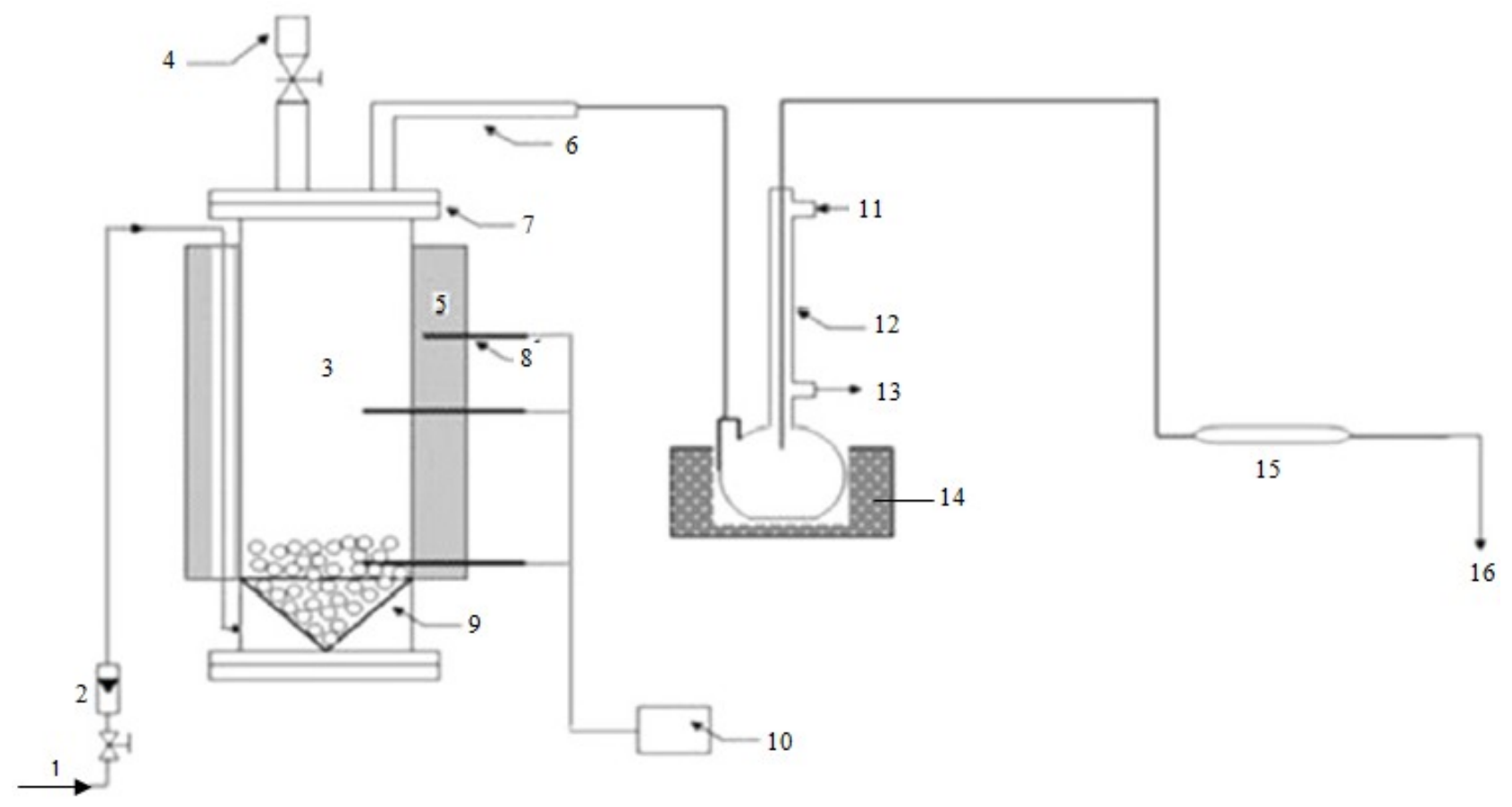

Figure 2. Schematic diagram of experimental setup: (1) $\mathrm{N}_{2}$ gas inlet, (2) flow meter, (3) lab-scale gratifier, (4) waste PCBs feeder, (5) electric furnace, (6) gas discharge, (7) flange, (8) thermocouples, (9) distributor, (10) temperature recorder, (11) cooling water supply, (12) condenser, (13) cooling water outlet, (14) ice bath, (15) silica gel, (16) flue gas outlet 
obtained from the slope of the graph of $\ln (1-X)$ vs. $1 / T$. The degree of conversion of waste $\mathrm{PCBs}, X$, is defined as:

$$
X=\frac{W_{0}-W}{W_{0}-W_{\infty}}
$$

where $W_{0}, W$ and $W^{\infty}$ represent initial, instantaneous and final masses of waste PCBs, respectively.

\subsection{Characterization of Pyro-Oil}

\subsubsection{Functional Groups Analysis}

The identification of polymer and monomer type of pyro-oils produced after the pyrolysis of waste PCBs was done using Fourier Transform Infrared Spectrometry (FT-IR) spectrometer (model Perkin Elmer, Spectrum 100/77353). All FT-IR spectra were recorded from 4000 to 600 $\mathrm{cm}^{-1}$. Components such as functional groups present in the pyro-oils and its transmittance will be indicated by the peaks formed in the graph obtained.

\subsubsection{Composition Analysis}

The quantitative analysis on the component exist in the pyro-oil was conducted using GCMS. About $2.0 \mathrm{ml} / \mathrm{min}$ of hydrogen was used as the carrier gas in the GC-MS (Agilent 6890 Series $/ 61530 \mathrm{H}$ ) and the diameter of the column (19091J-413/HP5) of $0.32 \mathrm{~mm}$ with thickness of
$2.25 \mathrm{~mm}$ and length of $30 \mathrm{~m}$ was used during the analysis. For the start phase, initial temperature used was $50{ }^{\circ} \mathrm{C}$ and was held for 3 minutes. For the final phase (B), the heating rate used was $10{ }^{\circ} \mathrm{C} / \mathrm{min}$ with initial temperature of $300{ }^{\circ} \mathrm{C}$ and holding time of 30 minutes. About $1 \mu l$ of pyro-oil was injected in each run.

\section{Experimental Procedure}

A schematic diagram of the experimental setup is shown in Figure 2. Based on TGA results, temperature of $\mathrm{PCBs}$ ' degradation was 250 to $350{ }^{\circ} \mathrm{C}$. Pyrolysis of waste PCBs was first carried out at $250{ }^{\circ} \mathrm{C}$ with the height of fluidized bed in the reactor was $44 \mathrm{~cm}$ from the base of the reactor. About $30 \pm 5 \mathrm{~g}$ of waste PCBs was weighed by electronic weighing scale

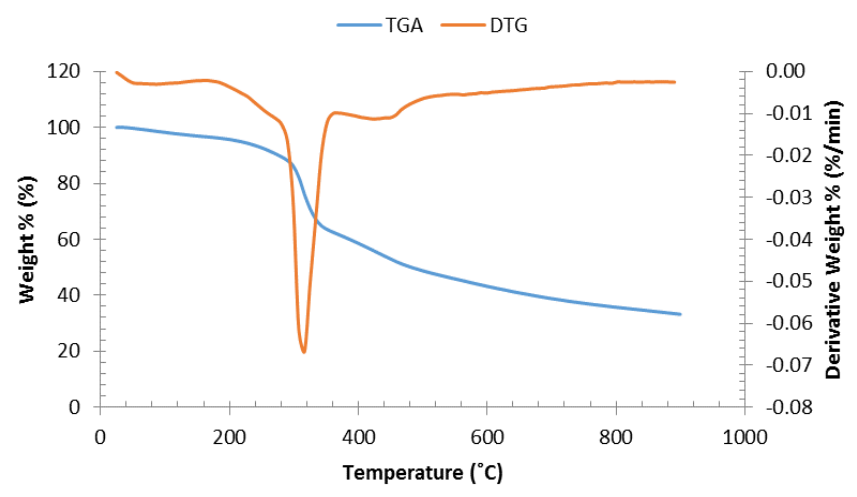

Figure 3. TG and DTG curve of waste PCBs

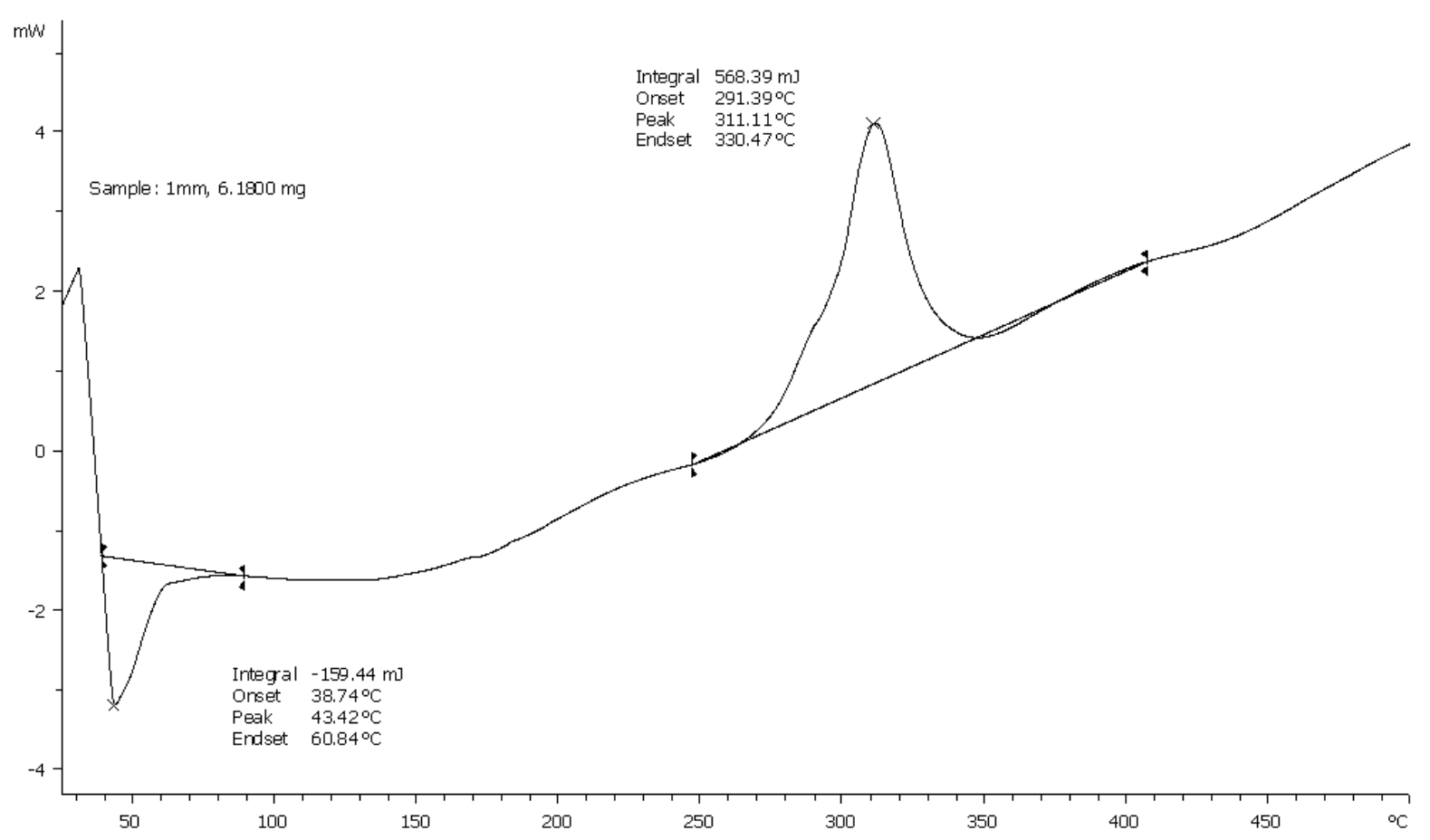

Figure 4. DSC diagram of waste PCBs at heating rate of $10{ }^{\circ} \mathrm{C} / \mathrm{min}$ 
(model AND, GF-300, Japan) and it was fed into the lab-scale fluidized bed reactor. A condenser to recover the dichloromethane vapor into liquid was fitted to the 3-neck flask and about $100 \mathrm{ml}$ of dichloromethane was used in the experiment. Water pipe was used as a cooling liquid in the condenser.

The reactor was flushed with $50 \mathrm{ml} / \mathrm{min}$ of nitrogen gas for 10 minutes in order to introduce an oxygen-free condition before the pyrolysis was started. Nitrogen gas flow rate fed into the reactor was monitored by flow meter (KOFLO/080714-02S, Japan). The diameter of the fluidized bed reactor was $3.8 \mathrm{~cm}$ with the length of $60.5 \mathrm{~cm}$. Temperature profile of the pyrolysis was monitored by Pico regulator. Utube glass was filled with silica gel to absorb moisture content thus, dry flue gas could be exited from the tube. The heating rate of the reactor of $10{ }^{\circ} \mathrm{C} / \mathrm{min}$ was set. Pyrolysis process was maintained for 1.5 hours. Pyro-oil was separated from dichloromethane using rotary vacuum evaporator (model Eyela, NN series, USA) at $90{ }^{\circ} \mathrm{C}$ about 40 minutes. Mass basis was used in calculating the yield of the products. Solid residue was separated from the bed and its' weight was determined to get the solid mass. The yield of the gas product was calculated by difference. The experiment was repeated by pyrolyzing PCBs waste with the presence of different catalysts such as FCC catalyst, ZSM-5 zeolite, H-Y zeolite and dolo- mite at optimum temperature with the ratio of 10:90. After identifying best catalyst to be used, the experiment was repeated using different ratios of catalyst to $\mathrm{PCBs}$ waste such as $20: 80,30: 70,40: 60$ and 50:50 and the results obtained were compared.

\section{Results and Discussion}

\subsection{Thermal Analysis of Waste PCBs}

Regions in the Derivative Thermogravimetry (DTG) curve show the thermal decomposition of organic matters and volatiles in the waste PCBs. The first weight loss region formed before $100{ }^{\circ} \mathrm{C}$ was due to the vaporization of moisture content in the waste PCBs. The second weight loss region formed after 100 ${ }^{\circ} \mathrm{C}$ was due to the decomposition of volatile matters. The final weight loss region formed after $400{ }^{\circ} \mathrm{C}$ was due to the removal of volatile and organic matters in the $\mathrm{N}_{2}$ purge. Figure 3 shows a multi-step decomposition of waste PCBs. The highest rate of waste PCBs' weight loss that occurs is indicated by the peak temperature of DTG curve. Thermal decomposition of waste PCBs resulted in major peak of temperature ranging from 250 to $400{ }^{\circ} \mathrm{C}$. The moisture content was $9.04 \%$ and the volatile matter was $90.6 \%$. The higher amount of volatile matter is a good indicator for potential pyro-oil produced from the pyrolysis. The first derivative peak temperature $\left(T_{p}\right)$ was $307.57{ }^{\circ} \mathrm{C}$. The peak

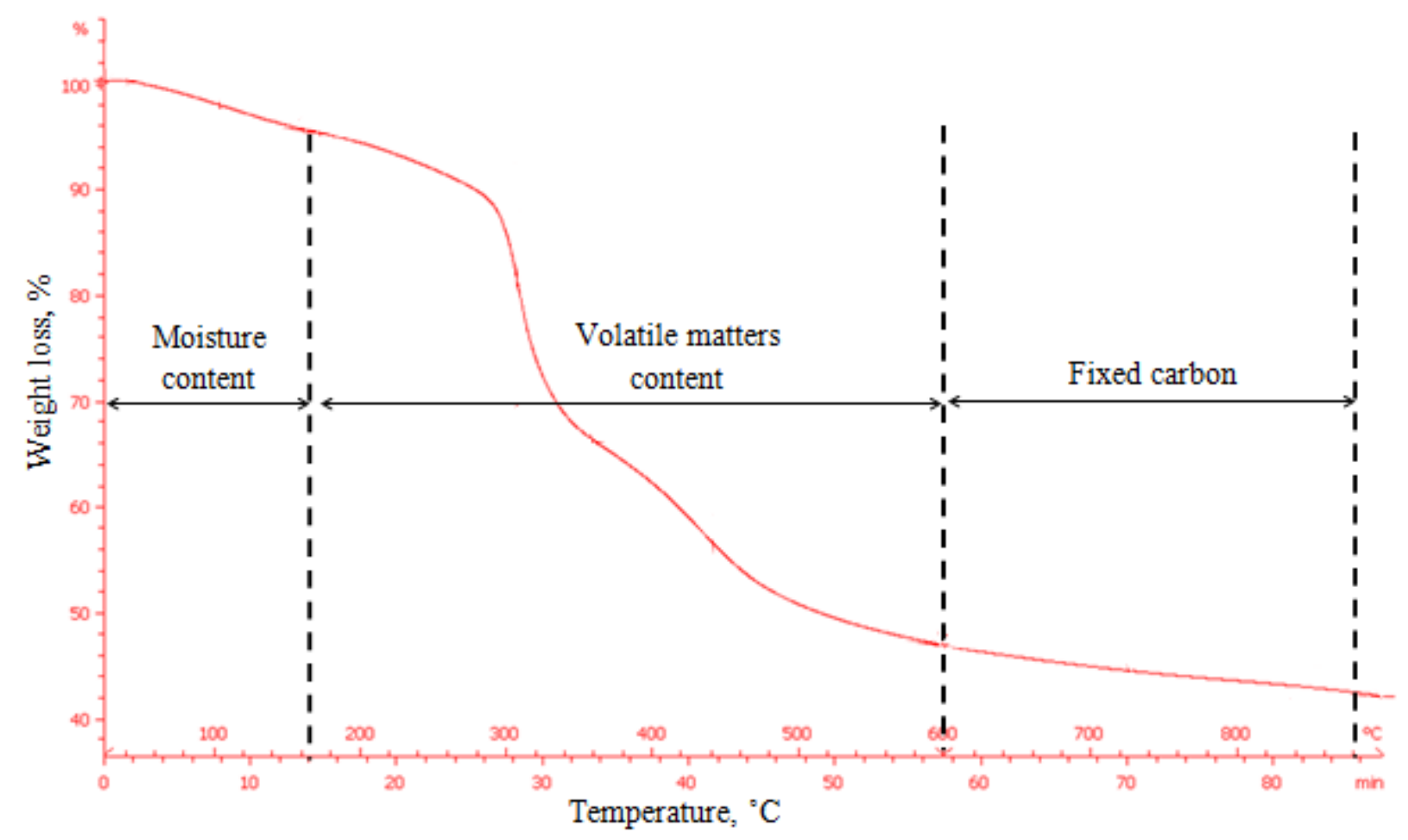

Figure 5. Proximate analysis of waste PCBs using TGA 
of the first derivative indicated the point of greatest rate of change on the weight loss curve. This peak is also referred as the inflection point.

\subsection{Differential Scanning Calorimetry (DSC) of Waste PCBs}

The glass transition temperature or phase transition temperature of waste PCBs was determined using DSC by measuring the amount of heat flow in or out under heating condition. At the heating rate of $10^{\circ} \mathrm{C} / \mathrm{min}$, the glass transition temperature of waste $\mathrm{PCBs}$ or $T_{g}$ occurred at $311.11{ }^{\circ} \mathrm{C}$. Glass transition temperature refers to temperature at which the changes occur in behavior of waste PCBs from being hard and brittle to being elastic and flexible. There will be no latent heat involved with the glass transition. The endothermic peak with a peak temperature of $43.42{ }^{\circ} \mathrm{C}$ was detected. The peak temperature is equivalent to the point at which the waste PCBs achieves its highest rate of curve. Figure 4 shows the DSC diagram of waste PCBs at heating rate of $10^{\circ} \mathrm{C} / \mathrm{min}$.

\subsection{Proximate Analysis of Waste PCBs}

Figure 5 shows the proximate analysis of waste PCBs using TGA. The proximate analyses are shown in Table 1 and comparisons with other proximate analyses from other researchers are also displayed. Volatile matter and ash are the main compositions of waste PCBs. High content of volatile matter causes more products such as oil and gases to be produced during the pyrolysis whilst the high percentage of ash content makes waste PCBs suitable to be used for fillers or composites. The results of the proximate analysis are within the range of literature values except for moisture content. Low moisture content is desirable as high moisture content of waste PCBs will consume more heat and result in lower oil yield. In this study, the mois-

Table 1. Proximate analyses of waste PCBs

\begin{tabular}{lcc}
\hline \multirow{2}{*}{ Properties } & \multicolumn{2}{c}{ Proximate analysis (wt.\%) of } \\
\cline { 2 - 3 } & $\begin{array}{c}\text { This } \\
\text { study }\end{array}$ & \multicolumn{1}{c}{ Literatures } \\
\hline Moisture & 4.59 & $0.44^{\mathrm{a}}, 0.28^{\mathrm{b}}, 1.23^{\mathrm{c}}$ \\
Volatile mat- & 48.20 & $21.08^{\mathrm{a}}, 27.47^{\mathrm{b}}, 37.17^{\mathrm{c}}$ \\
ter & & \\
Fixed carbon & 4.81 & $8.44^{\mathrm{a}}, 3.42^{\mathrm{b}}, 8.59^{\mathrm{c}}$ \\
Ash & 41.99 & $70.04^{\mathrm{a}}, 68.83^{\mathrm{b}}, 53.01^{\mathrm{c}}$ \\
\hline
\end{tabular}

a [17], b [18], c [19]

Table 2. Yield of waste PCBs' pyrolysis at different operating temperatures

\begin{tabular}{lcccc}
\hline $\begin{array}{c}\text { Temperature } \\
\left({ }^{\circ} \mathrm{C}\right)\end{array}$ & 250 & 275 & 300 & 350 \\
\hline Solid yield (\%) & 60.98 & 57.12 & 54.42 & 49.60 \\
$\begin{array}{l}\text { Liquid yield } \\
(\%)\end{array}$ & 12.81 & 16.03 & 12.82 & 17.61 \\
Gas yield a (\%) & 26.21 & 26.85 & 32.76 & 32.79 \\
\hline
\end{tabular}

${ }^{a}$ Gas yield was determined by difference

Table 3. Yield of waste PCBs' pyrolysis using different catalysts at $275^{\circ} \mathrm{C}$ and ratio catalyst to PCBs of 10:90

\begin{tabular}{cccccc}
\hline Catalyst & FCC & ZSM-5 & H-Y zeolite & Dolomite & Non-Catalytic \\
\hline Solid yield (\%) & 58.03 & 55.49 & 54.92 & 55.12 & 57.12 \\
Liquid yield (\%) & 22.43 & 19.20 & 19.24 & 14.40 & 16.03 \\
Gas yield a (\%) & 19.54 & 25.31 & 25.84 & 30.48 & 26.85 \\
\hline
\end{tabular}

a Gas yield was determined by difference

Table 4. Yield of waste PCBs' pyrolysis at various ratios of catalysts to PCBs at $275{ }^{\circ} \mathrm{C}$ using FCC catalyst

\begin{tabular}{ccccccc}
\hline Ratio & $10: 90$ & $20: 80$ & $30: 70$ & $40: 60$ & $50: 50$ & Non-Catalytic \\
\hline Solid yield (\%) & 58.03 & 55.16 & 54.84 & 53.72 & 52.82 & 57.12 \\
Liquid yield (\%) & 22.43 & 25.59 & 8.01 & 8.01 & 8.02 & 16.03 \\
Gas yield a (\%) & 19.54 & 19.25 & 37.15 & 38.27 & 39.16 & 26.85 \\
\hline
\end{tabular}

a Gas yield was determined by difference 
ture content of waste PCBs is higher than literature values because of PCB's delamination. The moisture absorption by waste PCBs increases with the risk of delamination. Delamination of PCBs occurs during processing because it is thermally stressed beyond its adhesion limitations. Besides that, high volatile content of waste PCBs in this study resulted in lower ash content to be obtained after combustion.

\subsection{Effect of Temperature on Pyrolysis Yields}

Chars, oils and gases were obtained during the pyrolysis of waste PCBs under noncatalytic and catalytic condition. Results are presented in Table 2, Table 3, and Table 4. The pyrolysis of waste PCBs was assumed to be completed because the solid yields obtained from the pyrolysis at different temperatures were almost similar. Observations were made and the shape of residue obtained after pyrolysis were about the same as the original ones. The color of residue was black and this could be due to formation of coke product through depolymerization reactions during the pyrolysis [22]. Solid yields of waste PCBs' pyrolysis were gradually decreased as the temperatures of pyrolysis increased due to more organic fractions of waste PCBs decomposed during the heating.

The liquid collected during the pyrolysis of waste PCBs was called pyro-oil and it was a mixture of organic and aqueous compounds. Researchers agreed that liquids formed during the pyrolysis could be the water and hydrocarbons by-product with the functional groups of

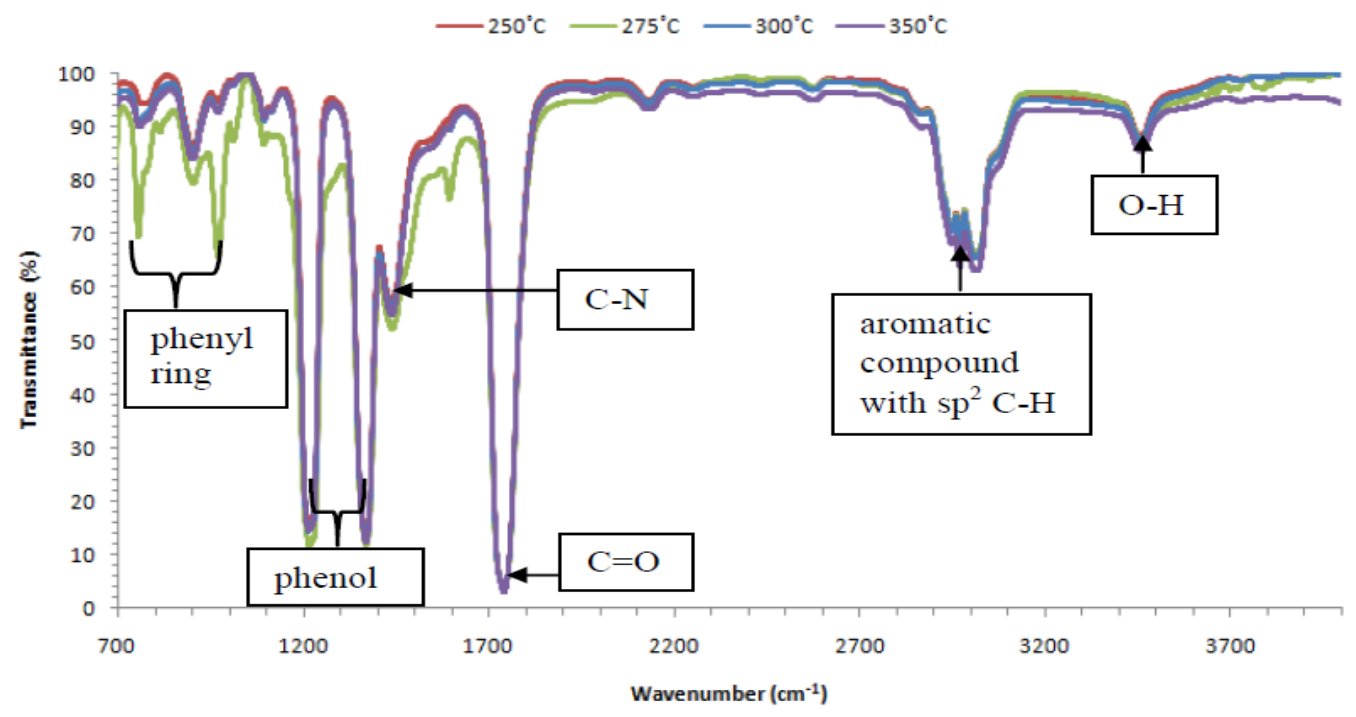

Figure 6. FT-IR results for different temperatures used in waste PCBs' pyrolysis

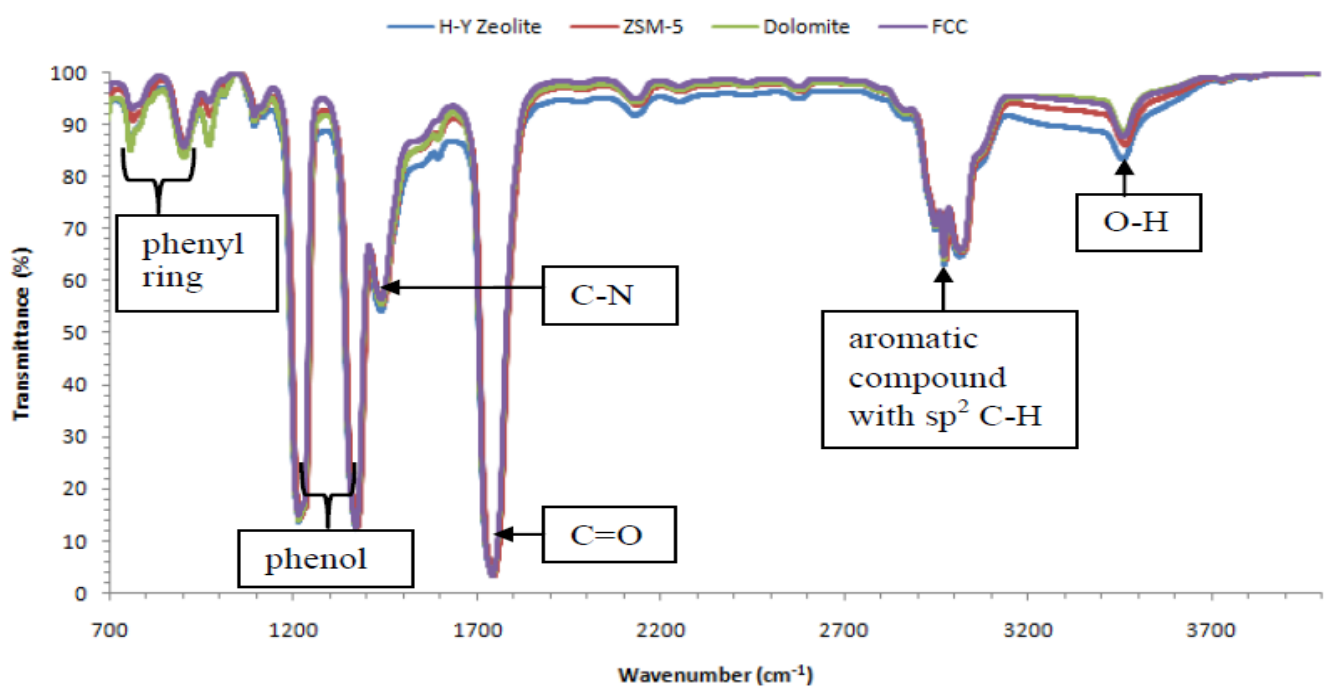

Figure 7. FT-IR results for different catalysts used in waste PCBs' pyrolysis 
$-\mathrm{OH},-\mathrm{COOH},-\mathrm{COO}$, etc. [22]. More pyro-oils were formed from waste PCBs' pyrolysis at 275 and $350{ }^{\circ} \mathrm{C}$ than pyrolysis at 250 and $300{ }^{\circ} \mathrm{C}$. Hence, the optimum temperature of pyrolysis could be 275 and $350{ }^{\circ} \mathrm{C}$. The overall comparisons on product yields need to be made before the optimum temperature could be determined. The gas yield from waste PCBs' pyrolysis increased as the temperature of pyrolysis increased. Gas product obtained in the waste PCBs' pyrolysis was about 26 to $33 \%$ of the total product. Chiang et al. reported that gas phase of waste PCBs' pyrolysis consisted of light hydrocarbon such as $\mathrm{C}_{1}-\mathrm{C}_{4}$, hydrogen gas, carbon dioxide, etc. [8].

The selected optimum temperature of waste
PCBs' pyrolysis was $275{ }^{\circ} \mathrm{C}$ due to high yield of oil product (about 16\% of total weight) and low yield of gaseous product (about 27\% of total weight) in comparison with other temperatures. It was intended to have high oil yield and low gas yield in the pyrolysis process so that more oils could be collected for feedstock whilst gas phase emitted must be in proportional amount. High gas yield in the pyrolysis would result in lower oil yield obtained. The product obtained based on selected optimum temperature was supported by the FT-IR and GC-MS analysis.

\subsection{Effect of Catalyst on Pyrolysis Yields}

Table 5. Compound's abundance at different temperatures

\begin{tabular}{lccccc}
\hline \multirow{2}{*}{ Compound } & $\begin{array}{c}\text { Retention time } \\
(\mathrm{min})\end{array}$ & \multicolumn{5}{c}{ Relative Abundance (\%) } \\
\cline { 3 - 6 } & 7.975 & $390^{\circ} \mathrm{C}$ & $275^{\circ} \mathrm{C}$ & $300^{\circ} \mathrm{C}$ & $350^{\circ} \mathrm{C}$ \\
\hline Phenol & 9.350 & 2.20 & 2.27 & 3.71 & 53.60 \\
1-hydroxy-2-methylbenzene & 9.717 & 2.39 & 2.23 & 3.93 & 5.26 \\
p-methylphenol & 10.967 & 1.22 & 1.35 & 2.78 & 3.79 \\
1-hydroxy-2,4- & & & & & \\
dimethylbenzene & 11.242 & 0.40 & 0.57 & 0.96 & 1.04 \\
1-ethyl-4-hydroxybenzene & 12.175 & 2.31 & 2.38 & 3.53 & 3.00 \\
m-Isopropylphenol & 12.350 & 0.34 & 0.10 & 0.18 & 0.19 \\
3-ethyl-5-methylphenol & 19.917 & 0.52 & 0.55 & 0.68 & 0.54 \\
$N$-(phenylmethylene) & 25.283 & 48.54 & 47.96 & 37.44 & 36.19 \\
Triphenyl phosphate & 26.083 & 2.19 & 2.31 & 0.18 & 1.15 \\
Diisooctyl phthalate & & & & & \\
\hline
\end{tabular}

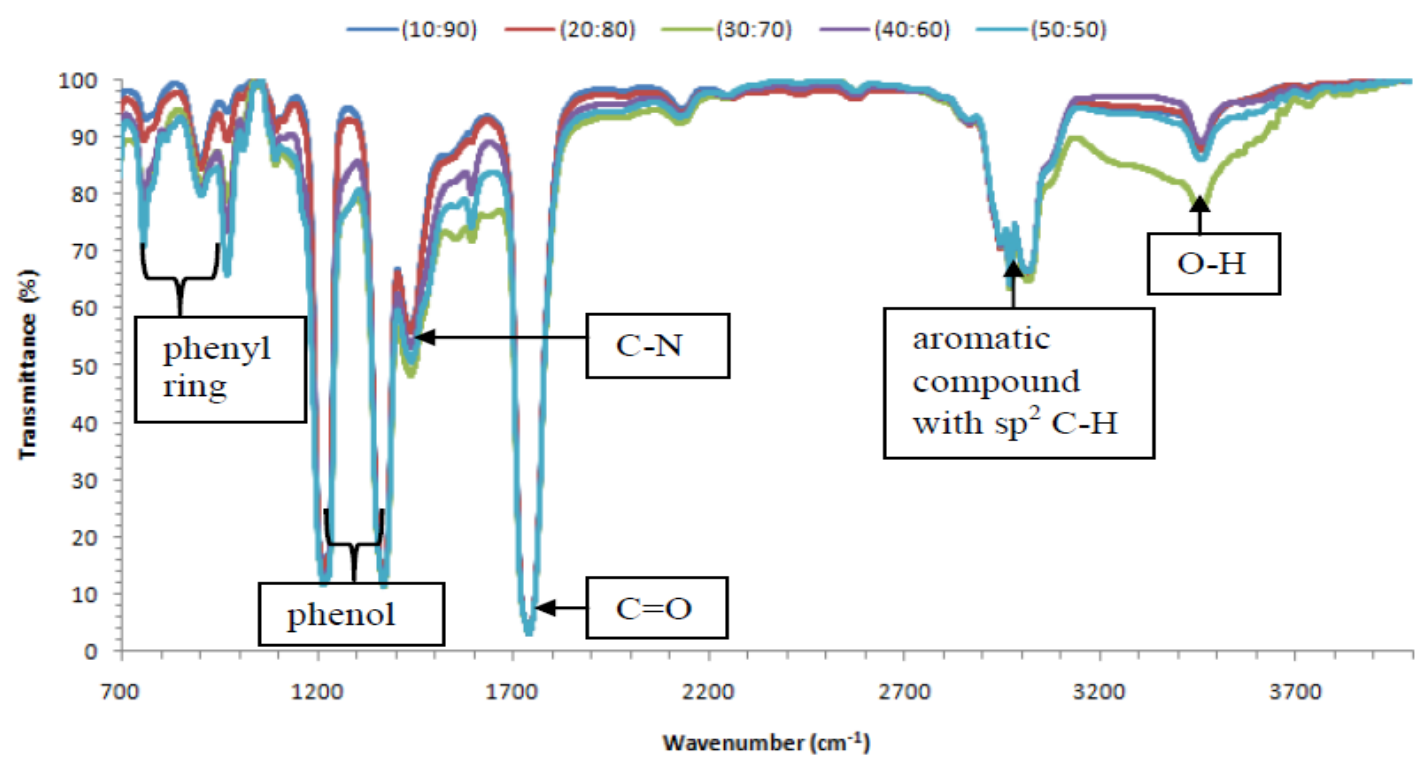

Figure 8. FT-IR results for different ratios used in waste PCBs' pyrolysis 
Solid yields obtained from pyrolysis were about $50 \%$ of the total weight for all catalyst used. Based on Table 2 and Table 3, liquid yields from the catalytic pyrolysis were higher than non-catalytic pyrolysis. The presence of catalyst reduced the pyrolysis temperature for achieving product conversion. Under non catalytic conditions, high temperature was required to reach a reasonable product conversion but with the presence of catalyst, the rate of reaction had been increased and eventually more liquids product could be collected [24]. More oils were collected from waste PCBs' pyrolysis of $275^{\circ} \mathrm{C}$ with the presence of FCC than other catalysts at the same condition. Comparing data between Table 2 and Table 3, it could be seen that the percentage of gas yield had been reduced under the catalytic pyrolysis and this explains that the presence of catalyst in the pyrolysis favors for liquid formation except for dolomite.

FCC was identified as the best catalyst to be used for pyrolyzing waste PCBs because more liquids were collected and at the same time,

Table 6. Compound's abundance with different catalysts

\begin{tabular}{|c|c|c|c|c|c|}
\hline \multirow{2}{*}{ Compound } & \multirow{2}{*}{$\begin{array}{l}\text { Retention time } \\
(\min )\end{array}$} & \multicolumn{4}{|c|}{ Relative Abundance (\%) } \\
\hline & & FCC & ZSM-5 & H-Y zeolite & Dolomite \\
\hline Phenol & 7.975 & 71.36 & 65.44 & 70.81 & 56.13 \\
\hline 1-hydroxy-2-methylbenzene & 9.342 & 3.05 & 2.60 & 3.15 & 1.90 \\
\hline p-methylphenol & 9.717 & 2.69 & 3.19 & 3.62 & 2.09 \\
\hline 1-hydroxy-2,4-dimethylbenzene & 10.967 & 1.56 & 1.21 & 1.74 & 0.99 \\
\hline 1-ethyl-4-hydroxybenzene & 11.242 & 1.19 & 0.77 & 1.11 & 0.57 \\
\hline m-Isopropylphenol & 12.167 & 4.00 & 3.72 & 4.13 & 2.46 \\
\hline 6-Octadecenoic acid & 22.342 & 0.28 & 0.48 & 0.28 & 0.19 \\
\hline p,p'-Isopropylidenebisphenol & 23.417 & 0.63 & 0.88 & 0.75 & 0.45 \\
\hline Triphenyl phosphate & 25.283 & 13.29 & 18.89 & 11.84 & 34.05 \\
\hline Diisooctyl phthalate & 26.083 & 1.96 & 2.82 & 2.58 & 1.16 \\
\hline
\end{tabular}

Table 7. Compound's abundance with different ratios

\begin{tabular}{|c|c|c|c|c|c|c|}
\hline \multirow{2}{*}{ Compound } & \multirow{2}{*}{$\begin{array}{l}\text { Retention time } \\
(\text { min) }\end{array}$} & \multicolumn{5}{|c|}{ Relative Abundance (\%) } \\
\hline & & $10: 90$ & $20: 80$ & $30: 70$ & 40:60 & $50: 50$ \\
\hline Phenol & 7.983 & 71.36 & 42.60 & 38.38 & 51.981 & 59.69 \\
\hline 1-hydroxy-2-methylbenzene & 9.350 & 3.05 & 1.69 & 1.45 & 1.30 & 1.83 \\
\hline p-methylphenol & 9.725 & 2.69 & 1.96 & 1.83 & 2.19 & 2.38 \\
\hline 1-hydroxy-2,4-dimethylbenzene & 10.967 & 1.56 & 1.06 & 0.95 & 1.04 & 1.04 \\
\hline 1-ethyl-4-hydroxybenzene & 11.242 & 1.19 & 0.71 & 0.61 & 0.71 & 4.77 \\
\hline m-Isopropylphenol & 12.167 & 4.00 & 3.52 & 3.03 & 3.92 & 1.63 \\
\hline$N$-(phenylmethylene) & 19.908 & 0.28 & 1.05 & 1.10 & 1.00 & 0.58 \\
\hline Pentadecanenitrile & 20.458 & 0.63 & 0.40 & 0.34 & 0.48 & 11.13 \\
\hline Triphenyl phosphate & 25.283 & 13.29 & 45.23 & 50.33 & 37.25 & 14.05 \\
\hline Diisooctyl phthalate & 26.083 & 1.96 & 1.78 & 1.97 & 0.14 & 2.90 \\
\hline
\end{tabular}


Table 8. ICP analysis of waste PCBs and solid residue

\begin{tabular}{cccc}
\hline Waste PCBs (mg/l) & $\begin{array}{c}\text { Solid residue (mg/l) } \\
\text { (Non-catalytic condition) }\end{array}$ & $\begin{array}{c}\text { Solid residue (mg/l) } \\
\text { (Catalytic condition) }\end{array}$ \\
\hline $\mathrm{Cu}$ & 5.850 & 6.420 & 4.336 \\
$\mathrm{Cd}$ & $\mathrm{ND}$ & $\mathrm{ND}$ & $\mathrm{ND}$ \\
$\mathrm{Zn}$ & 0.446 & 0.205 & 0.470 \\
$\mathrm{Ba}$ & $\mathrm{ND}$ & 0.005 & $\mathrm{ND}$ \\
$\mathrm{Ca}$ & 4.078 & 4.651 & 2.416 \\
$\mathrm{Mn}$ & 0.007 & 0.007 & 0.002 \\
$\mathrm{Na}$ & $\mathrm{ND}$ & $\mathrm{ND}$ & $\mathrm{ND}$ \\
$\mathrm{La}$ & 0.004 & 0.004 & 0.006 \\
$\mathrm{Li}$ & 0.009 & 0.009 & 0.009 \\
$\mathrm{Sr}$ & 0.008 & 0.009 & 0.006 \\
$\mathrm{~K}$ & $\mathrm{ND}$ & 0.015 & $\mathrm{ND}$ \\
$\mathrm{As}$ & $\mathrm{ND}$ & $\mathrm{ND}$ & $\mathrm{ND}$ \\
$\mathrm{Pb}$ & 0.009 & $\mathrm{ND}$ & $\mathrm{ND}$ \\
$\mathrm{Cr}$ & $\mathrm{ND}$ & $\mathrm{ND}$ & $\mathrm{ND}$ \\
$\mathrm{Fe}$ & $\mathrm{ND}$ & 0.005 & $\mathrm{ND}$ \\
\hline
\end{tabular}

$\mathrm{ND}=$ Not Detected

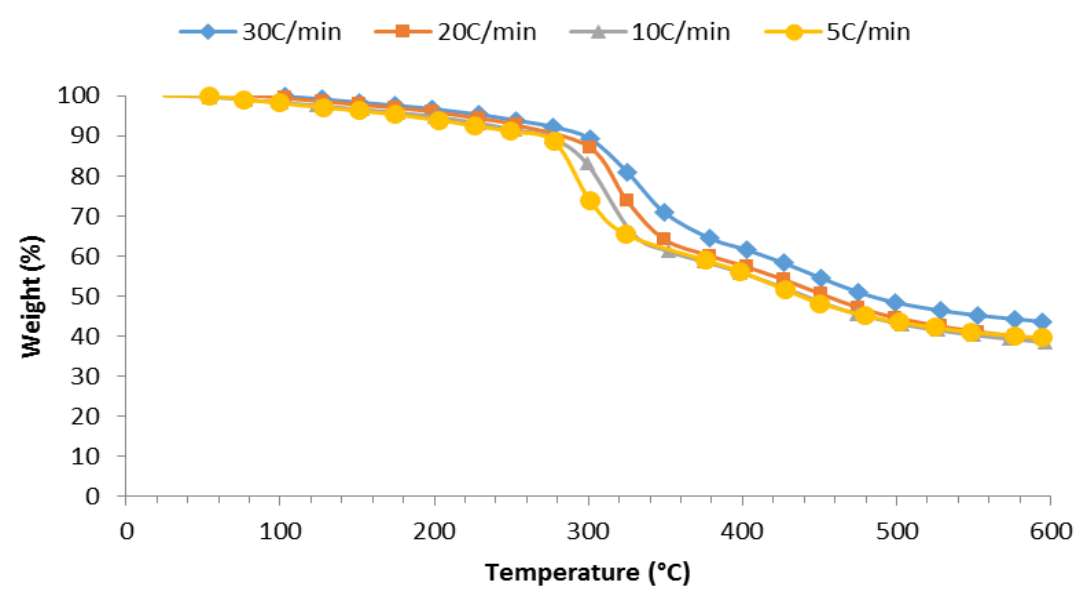

Figure 9. TG curve of waste $\mathrm{PCBs}$ at different heating rates

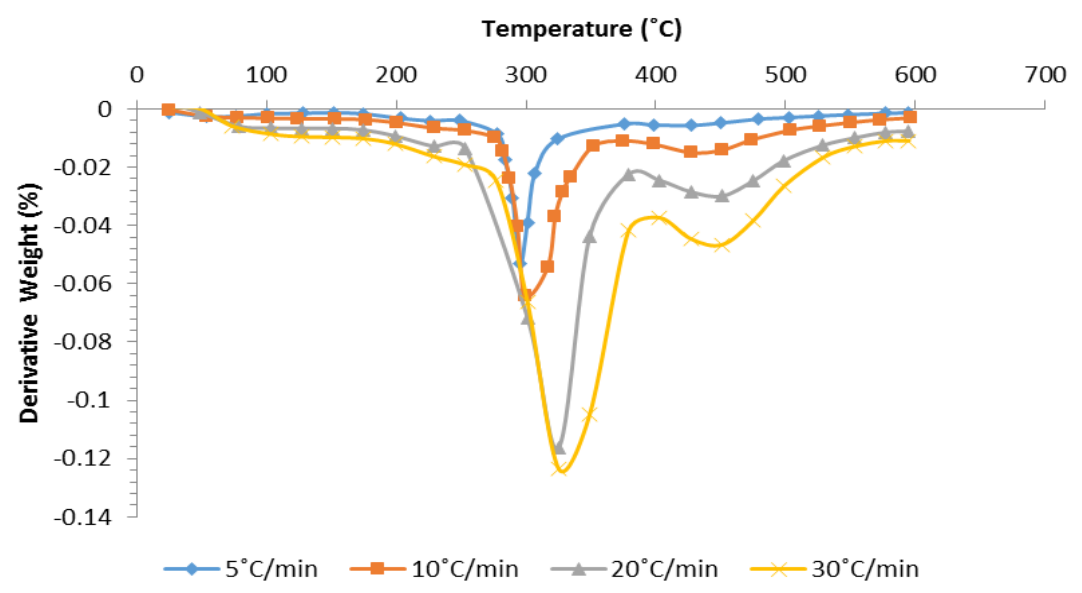

Figure 10. DTG curve of waste PCBs at different heating rates 
lesser gas was emitted. FCC is a typical catalyst used for cracking the crude petroleum of large hydrocarbon molecules into smaller hydrocarbon molecules such as gasoline in the petroleum refining industries to date [24]. Dolomite was seen as the least suitable catalyst to be used in the waste PCBs' pyrolysis due to the opposite product obtained i.e. higher gaseous product generated whereas lower liquid product formed. Zeolite based catalysts such as ZSM-5 and H-Y zeolite have a potential to be used in waste PCBs' pyrolysis because there are significant increments in the liquid yields in comparison with the product yields obtained under the non-catalytic pyrolysis. Zeolite based catalyst and FCC have been identified to have good ratio of $\mathrm{SiO}_{2} / \mathrm{Al}_{2} \mathrm{O}_{3}$ where the incorporated metals can increase the catalyst acidity. The carbonium ion theory was used to explain why the catalytic acidity was effective in enhancing lower carbon chain molecules [24]. Coke formation in the pyrolysis was greatly reduced with the formation of many low carbon chains molecules.

\subsection{Effect of Ratio on Pyrolysis Yields}

Different ratios of FCC catalyst to waste PCBs were used in the experiment to determine the best ratio to be used in the pyrolysis. Higher ratio of FCC to waste PCBs used will promote lesser solid yields obtained and this has been reflected in Table 4. This explains that more organic portion of waste PCBs have been degraded with large amount of FCC used. In Table 4, it can be seen that liquid yields

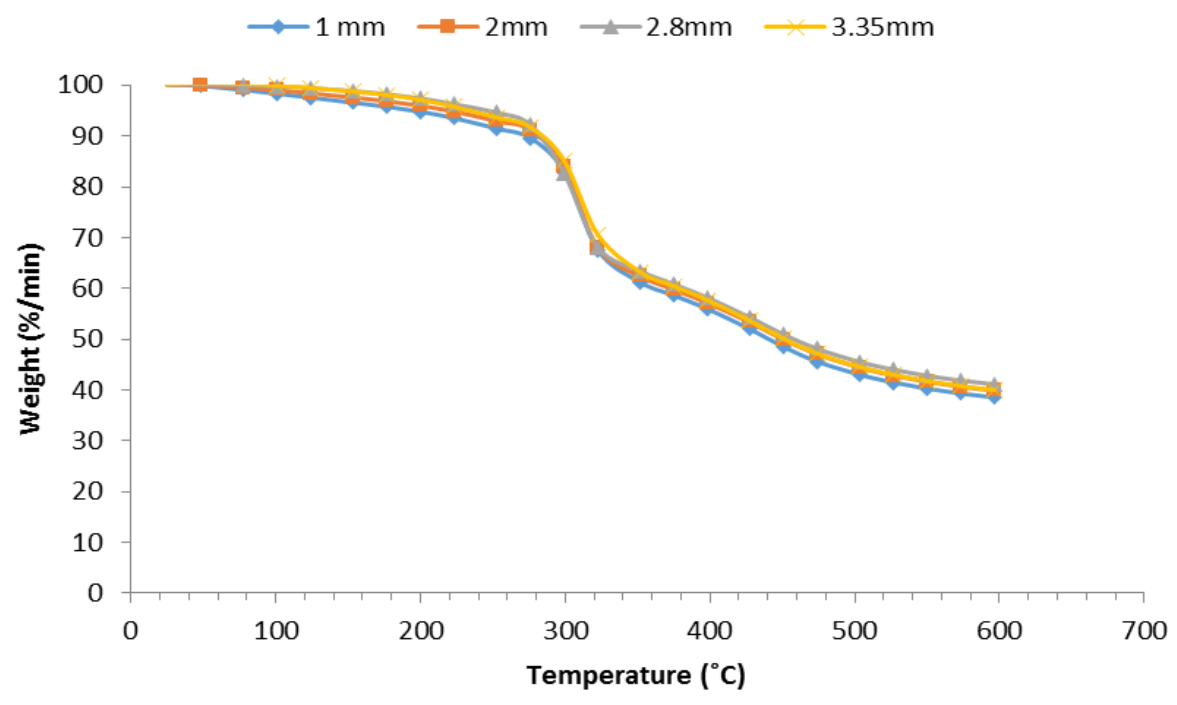

Figure 11. TG curve of waste PCBs at different particle sizes

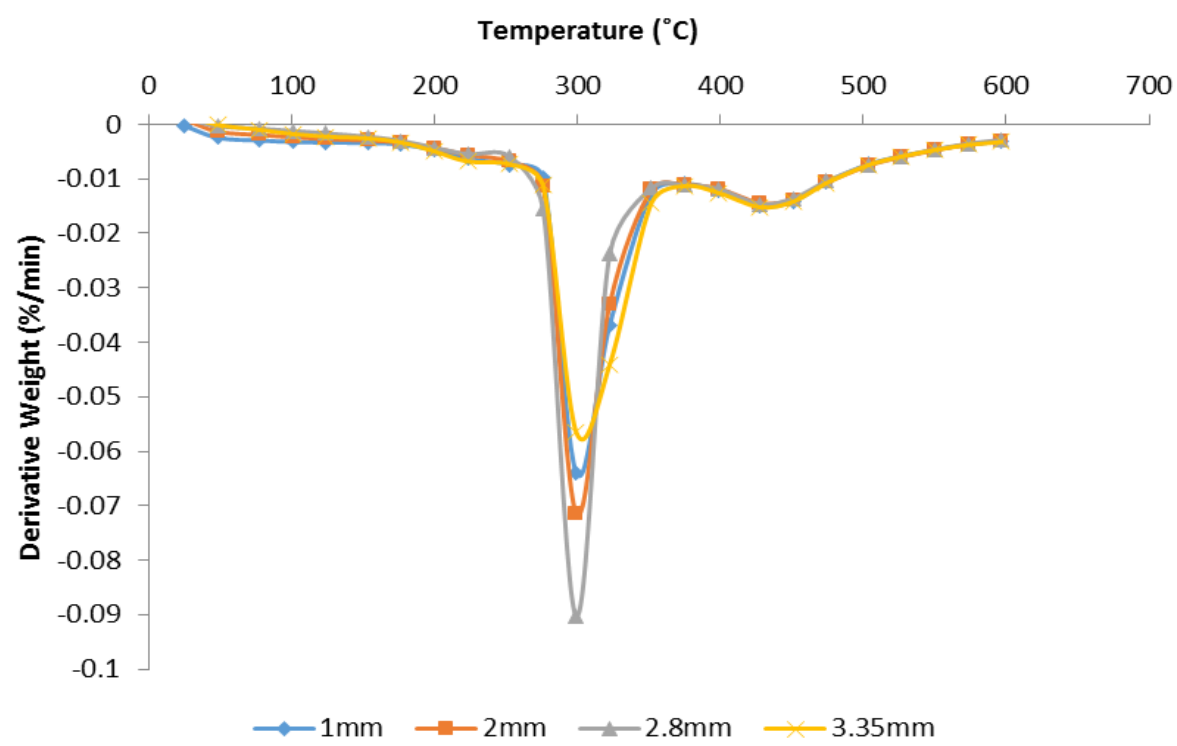

Figure 12. DTG curve of waste PCBs at different particle sizes 
from the pyrolysis with ratio of 10:90 and 20:80 is comparatively higher than pyrolysis at different ratios such as 30:70, 40:60 and 50:50. Significant drop of liquid yield for ratios of 30:70, 40:60 and 50:50 than non-catalytic condition are hugely due to huge amount of gases formed during the pyrolysis. Higher catalyst fed in the pyrolysis process will promote the secondary reactions leading to further cracking of the carbon-carbon bonding. Thus, shorter hydrocarbon chains namely gaseous product will be generated. This can be evident as tabulated in Table 4.

Gas phase obtained in the waste PCBs' pyrolysis was about 19 to $40 \%$ of the total weight of solid, liquid and gas phase. It has been discussed earlier that gas yields for ratio of 30:70, 40:60 and 50:50 was high and this is due to many large hydrocarbon molecules had been cracked into smaller chain of hydrocarbon molecules by FCC. 10:90 was selected as the best ratio to be used in accelerating the pyrolysis of waste PCBs due to higher collection of liquid product and at the same time, lesser gas was emitted. Other ratios such as 30:70, 40:60 and 50:50 are not suitable to be used as the liquid yields are low and at the same time, the gas yields are pretty high and this scenario is not much preferred in the pyrolysis process. There is a small discrepancy on product yields for ratio of $10: 90$ and $20: 80$ but ratio of $10: 90$ was selected based on the FT-IR and GC-MS results.

\subsection{FT-IR Results}

Fourier Transform Infrared Spectrometry (FT-IR) spectrometer (model Perkin Elmer, Spectrum 100/77353) was used to obtain an in- frared spectrum of pyro-oils and identify the polymer and monomer type of pyro-oils produced after the pyrolysis of waste PCBs. The provided IR spectrums could represent functional groups in the oil. It is obvious that functional groups identified are the same although different operating temperature was used in the waste PCBs' pyrolysis. The main functional groups detected are aromatic out-of-plane ring bends (phenyl ring substitution bands) for 900$700 \mathrm{~cm}^{-1}$, alcohols (C-O stretch) for 1150-1050 $\mathrm{cm}^{-1}$, phenols (C-O stretch) for $1330-1390 \mathrm{~cm}^{-1}$ and $1260-1180 \mathrm{~cm}^{-1}$, amine $(\mathrm{C}-\mathrm{N}$ stretch) for 1400-1300 $\mathrm{cm}^{-1}$, aldehydes or ketones ( $\mathrm{C}=\mathrm{O}$ stretch) for $1750-1710 \mathrm{~cm}^{-1}$, aromatic compounds with $\mathrm{sp}^{2} \mathrm{C}-\mathrm{H}$ stretch for 3100-3020 $\mathrm{cm}^{-1}$ and alcohols with $\mathrm{O}-\mathrm{H}$ stretch for 3600$3200 \mathrm{~cm}^{-1}$. Transmittance of main functional groups for $275{ }^{\circ} \mathrm{C}$ was relatively lower than other temperatures and this indicated that higher concentration of the functional groups had been detected for $275{ }^{\circ} \mathrm{C}$ and the purity of these functional groups were high as well. Figure 6 proved that $275^{\circ} \mathrm{C}$ was the optimum temperature of pyrolyzing waste PCBs as discussed in the previous discussion.

In Figure 7, it can be seen that the functional groups for waste PCBs are the same despite different catalysts have been used to accelerate the pyrolysis process. The main functional groups detected are the same as the functional groups detected in Figure 6. Hence, it can be concluded that the addition of catalyst will only accelerate reaction rate for pyrolysis without interfering the production formation. FT-IR results for different ratios (Figure 8) have been compared and the main functional groups detected are the same as functional

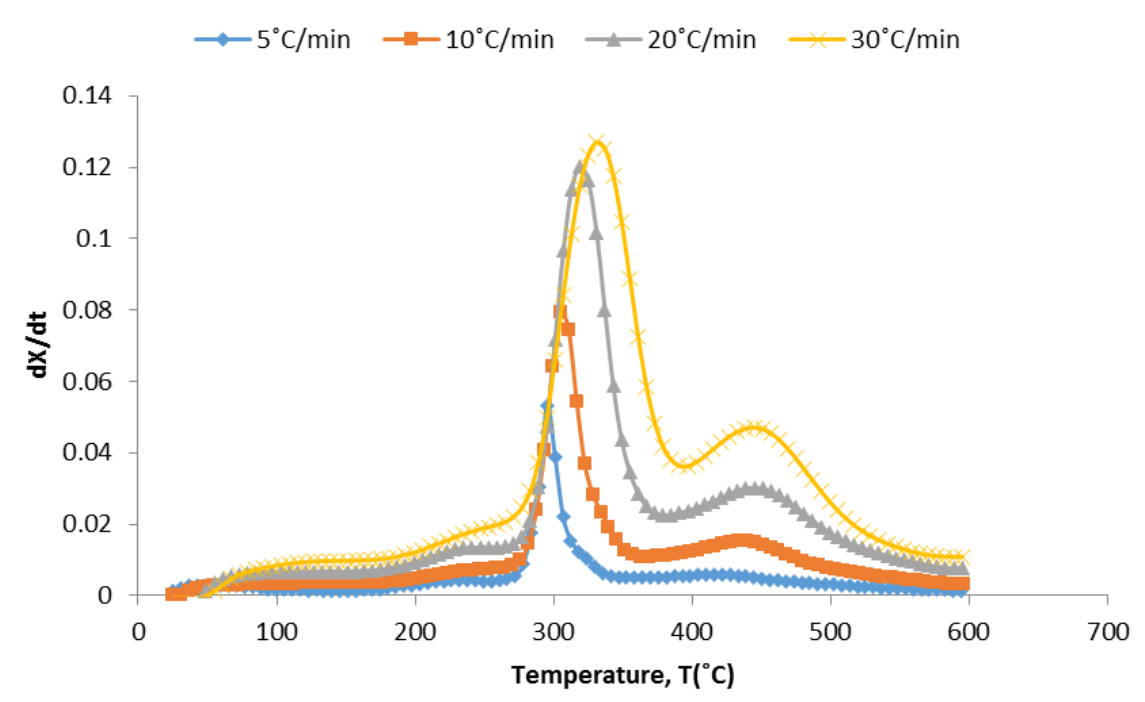

Figure 13. Variation of the instantaneous reaction rate with temperature at different heating rates for thermal decomposition of waste PCBs 
groups detected in Figure 6 and Figure 7. In Figure 8, the functional groups at ratio 50:50 recorded the high transmittance in comparison with other ratios. But the pyro-oil yield for ratio of 50:50 was relatively lower than other ratios used and hence ratio of 50:50 was not a suitable ratio to be used during the pyrolysis. Besides that, cost of materials is also taken into consideration as it is not economical to use high ratio of catalyst to waste PCBs and eventually leads to catalyst wastage. Ratio of 10:90 was selected as the best ratio since the concentration of functional groups detected was higher at ratio 10:90 than at 20:80. The selection will be further confirmed after GC-MS results have been analyzed.

\subsection{GC-MS Results}

GC-MS was used to separate and analyze compounds that can be vaporized without decomposition. In Table 5, phenol and triphenyl phosphate are the main compounds can be found in the pyro-oil. About $39 \%$ to $46 \%$ of phenol and about $36 \%$ to $49 \%$ of triphenyl phosphate were identified present in the pyro-oil. These two main products could be formed from the cracking of the laminates manufactured as boards for the assembly of PCB. The characteristics of laminates manufactured depends on the requirements of the circuit. Depending on the requirements such as dielectric constant, material strength and fire retardants, some laminates could be made from a mixture of Teflon, phenolic cotton paper, cotton paper and epoxy, woven glass and epoxy, matte glass and polyester, cotton paper and epoxy, non-woven glass and epoxy, or woven glass and polyester. Both compounds namely phenol and triphenyl phosphate are important precursor for downstream processing industry such as plastic

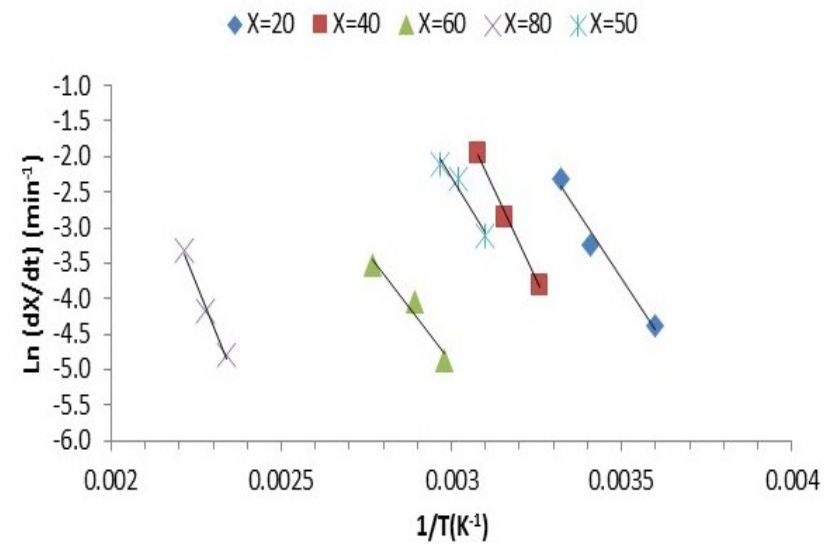

Figure 14. $\ln (d X / d t)$ vs. $1 / T$ for thermal decomposition of waste PCB manufacturing, softener, etc. Other compounds identified are mostly aromatic out-of-plane ring bends (phenyl ring substitution bands).

In Table 6, it could be seen that with the addition of catalyst, amount of phenol detected in the pyro-oil was increased tremendously in comparison with non-catalytic condition. More than $65 \%$ of phenol is present in the pyro-oil for all catalysts used except dolomite. The presence of catalysts not only accelerate reaction rate of pyrolysis but also favor the phenol production in the pyro-oil. The main compounds identified present in the pyro-oil for catalytic condition are almost the same as the main compounds detected in the pyro-oil under noncatalytic condition.

It is noted that high amount of phenol content detected present in the pyro-oil when ratio of 10:90 was used in comparison with other ratios. Higher amount of catalyst used do not favor for higher phenol yield. In the previous discussion, ratio of 10:90 is chosen as the best ratio as higher phenol content detected present in the pyro-oil than other ratios. The data as presented in Table 7 supports that ratio of $10: 90$ is the best ratio to be applied in the waste PCBs' pyrolysis.

\subsection{ICP-MS Results}

Metal analysis in the waste PCBs and solid residue can be done using inductively coupled plasma mass spectrometry (ICP-MS). It is important to identify the range of metals and nonmetals concentrations in the waste PCBs and solid residue so that a proper management of waste PCBs can be adopted for recycling the metallic fractions. Table 8 shows the ICP analysis of waste PCBs and pyrolysis solid residue. Metal concentration for both samples were about the same. Cadmium $(\mathrm{Cd})$, sodium $(\mathrm{Na})$,

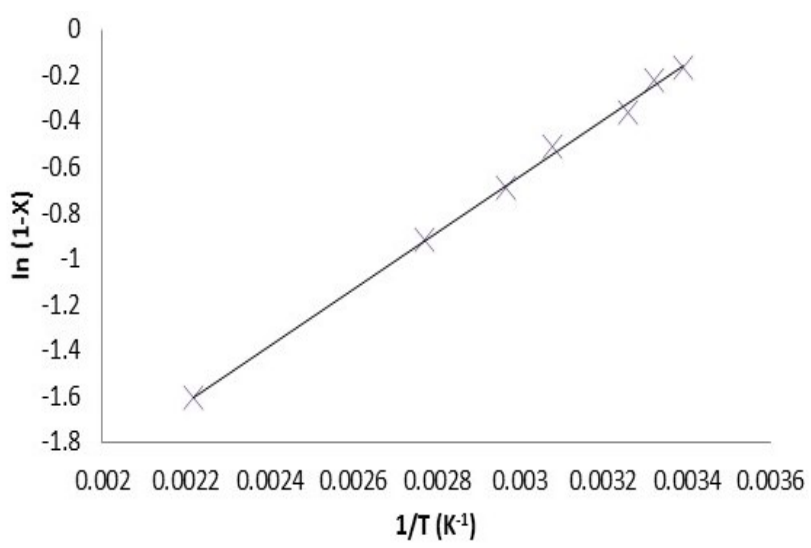

Figure 15. $\ln (1-X)$ vs. $1 / T$ for thermal decomposition of waste PCBs 
arsenic (As) and chromium (Cr) were not detected in both the waste PCBs and solid residue after pyrolysis. In Table 8, copper $(\mathrm{Cu})$ and calcium (Ca) were the highest concentration of metal elements detected present in the waste $\mathrm{PCBs}$ and solid residue. Other metals also detected in the waste PCBs and solid residue were zinc $(\mathrm{Zn})$, barium $(\mathrm{Ba})$, manganese $(\mathrm{Mn})$, lanthanum (La), lithium (Li), strontium (Sr), potassium $(\mathrm{K}$,$) lead (\mathrm{Pb})$, and iron $(\mathrm{Fe})$. However, metal concentration of $\mathrm{Fe}, \mathrm{K}$ and $\mathrm{Ba}$ were only present in the solid residue under non catalytic condition and this could be due to the randomness of selecting samples for metal analysis. Metal deposited in the raw waste PCBs could be varied due to various type of $\mathrm{PCBs}$ depending on the requirement and characteristics such as assembly for television, computers or mobile phones. The collected waste PCBs could be mixed together during the crushing or shredding and this could explain why the irregularities of metal concentration were detected in the ICP-MS results.

\subsection{Kinetics of Waste PCBs' Degradation}

By interpreting the TGA data, information regarding the number of stages processes and the kinetics constants of waste PCBs were obtained. The activation energy and the rate of waste PCBs' decomposition must be known for designing good pyrolytic equipment.

\subsubsection{Effect of Heating Rate}

Figures 9 and 10 show the TG and DTG curves obtained from the pyrolysis of waste PCBs at different heating rates namely 5, 10, $20,30^{\circ} \mathrm{C} / \mathrm{min}$. The curves of TG (Figure 9) and DTG (Figure 10) were shifted to the higher temperature when higher heating rate was used. Moreover, DTG peak temperature also increased when the heating rate used increased. Heating rate is important in the pyrolysis as high heating rate promotes the short reaction time and this leads to higher temperature is required for waste PCBs to be degraded. Hence, this explains why TG and DTG curves were shifted to the right side when higher heating rate was used in the pyrolysis.

\subsubsection{Effect of Particle Size}

Figures 11 and 12 show the TG and DTG curves obtained from the pyrolysis of waste PCBs at different particle sizes of $1 \mathrm{~mm}, 2 \mathrm{~mm}$, $2.8 \mathrm{~mm}$ and $3.35 \mathrm{~mm}$. It was observed that the curves in the Figure 11 were not shifted to any side and it is unanimous. However, as the par- ticle size increased, peak temperature in Figure 12 also increased except particle size of 3.35 $\mathrm{mm}$. Particle size do affect the pyrolysis of waste PCBs as large particle size will influence the temperature gradient during pyrolysis and this leads to the increment of solid yield and reduction in liquid and gas yield. For the same heating rate, non-metallic fractions of large particle size waste PCBs tend to undergo the incomplete decomposition and hence lesser liquid and gas yield can be collected in comparison with smaller particle sizes.

\subsubsection{Rate of Reaction}

Figure 13 shows the variations in the rate of conversion $(d X / d t)$ during the thermal decomposition of waste PCBs with respect to temperature. Two distinct peaks were observed for all the heating rates in the Figure 13 and this showed that waste PCBs' degradation was not a single step decomposition. It can be seen that the peaks shifted towards the range of high temperature as higher heating rate was used. This is because high heating rate will result in shorter retention time and eventually wastes PCBs require higher temperature to be decomposed.

\subsubsection{Activation Energy}

In Figure 14, the average of activation energy value obtained was $72.55 \mathrm{~kJ} / \mathrm{mol}$ for $\mathrm{X}=$ 0.2 to 0.8 . The activation energy obtained was considered low and hence no large amount of energy was required to initiate the reaction. Based on Figure 15, with an estimated slope value of 1386 and with the average activation energy value of $72.55 \mathrm{~kJ} / \mathrm{mol}$, using equation (4), the order of reaction which is the degree of waste PCB conversion was 6 . This low activation energy with low degree of conversion are important factors for upscaling the pyrolysis of waste PCB to the industrial scale.

\section{Conclusion}

Pyrolysis of waste PCBs are best to be carried out at $275{ }^{\circ} \mathrm{C}$ with the presence of FCC catalyst and the suitable ratio of catalyst to waste PCBs is 10:90. Pyrolysis of waste PCBs will produce chars, pyro-oil and gases. After pyrolysis, the dimension of waste PCBs remains the same and it becomes black in color.

This occurrence could be due to formation of coke product through depolymerization reactions during the pyrolysis. Pyro-oil produced has been identified to have functional groups of mainly aromatic and phenyl compounds and 
the analysis shows that pyro-oil has the potential to be used as the fuel or chemical feedstock for the downstream processing. The metal concentrations in the waste PCBs and solid residue show that the metal composition before and after pyrolysis are about the same as the melting point of metals are much higher than pyrolysis temperature used in this research and hence most of the metals remain in the solid residue after pyrolysis. Metals detected present in the waste $\mathrm{PCBs}$ and solid residue are $\mathrm{Zn}, \mathrm{Ba}, \mathrm{Mn}, \mathrm{La}, \mathrm{Li}, \mathrm{Sr}, \mathrm{K}, \mathrm{Pb}$, and $\mathrm{Fe}$.

In the kinetic study of PCBs' degradation, the heating rate plays vital role in influencing the reaction rate of pyrolysis. High heating rate will result in higher peak temperature as more heat is needed to decompose the waste PCBs. Besides that, particle size does affect the pyrolysis process. The large particle size will influence the temperature gradient during pyrolysis and this leads to the increment of solid yield and reduction in liquid and gas yield. The average activation energy value obtained was 72.55 $\mathrm{kJ} / \mathrm{mol}$ for conversion, $X=0.2$ to 0.8 . The activation energy obtained was considered relatively low and no large amount of energy was required in initiating the reaction. In short, PCB waste have the potential to be used as fuel or chemical feedstock for downstream processing and the feasibility of PCBs' catalytic pyrolysis as the better recycle technology for PCB waste has been confirmed.

\section{Acknowledgement}

The authors would like to express gratitudes to Dr. Mohammad M.A. Al-Obaidi and Miss Liew Mei Yi for the assistance during experimental and analysis work and to the Universiti Putra Malaysia in particular the Department of Chemical and Environmental Engineering for facility and funding.

\section{References}

[1] Guo, J., Cao, B., Guo, J., Xu, Z. (2008). A Plate Produced by Nonmetallic Materials of Pulverized Waste Printed Circuit Boards, Environmental Science and Technology, 42: 5267-5271.

[2] Department of Environment, Malaysia. (Accessed on 8 November 2011). Quantity of E-Waste Generated in Year 2006 to 2009. Online at < http://www.doe.gov.my/portal/>.

[3] Nui, X., Li, Y. (2007). Treatment of Waste Printed Wire Boards in Electronic Waste for Safe Disposal, Journal of Hazardous Materials, 145: 410-416.
[4] Veit, H.M., Bernardes, A.M., Ferreira, J.Z., Tenório, J.A.S., Malfatti, C.de F. (2006). Recovery of Copper from Printed Circuit Boards Scraps by Mechanical Processing and Electrometallurgy, Journal of Hazardous Materials, 137: 1704-1709.

[5] Cui, J., Forssberg, E. (2003). Mechanical Recycling of Waste Electric and Electronic Equipment: A Review, Journal of Hazardous Materials, 99: 243-263.

[6] Zhou, Y., Qiu, K. (2010). A New Technology for Recycling Materials from Waste Printed Circuit Boards, Journal of Hazardous Materials, 175: 823-828.

[7] Duan, H., Huo, K., Li, J., Zhu, X. (2011). Examining the Technology Acceptance for Dismantling of Waste Printed Circuit Boards in Light of Recycling and Environmental Concerns, Journal of Environmental Management, 92: 392-399.

[8] Chiang, H.L., Lin, K.H., Lai, M.H., Chen, T.C., Ma, S.Y. (2007). Pyrolysis Characteristics of Integrated Circuit Boards at Various Particles Sizes and Temperatures, Journal of Hazardous Materials, 149: 151-159.

[9] Zheng, Y., Shen, Z., Cai, C., Ma, S., Xing, Y. (2009). The Reuse of Nonmetals Recycled from Waste Printed Circuit Boards as Reinforcing Fillers in the Polypropylene Composites, Journal of Hazardous Materials, 163: 600-606.

[10] Yamawaki, T. (2003). The Gasification Recycling Technology of Plastic WEEE Containing Brominated Flame Retardants, Fire and $M a$ terials, 27: 315-319.

[11] Yokoyama, S., Iji, M. (1995). Recycling of Thermosetting Plastic Waste from Electronic Component Production Processes, IEEE International Symposium 06/1985.

[12] Sohaili, J., Muniyandi, S.K., Mohamad, S.S. (2012). A Review on Printed Circuit Board Recycling Technology, Journal of Emerging Trends and Engineering Applied Science, 3: 12-18.

[13] Braun, D., von Gentzkow, W., Rudolf, A.P. (2001). Hydrogenolytic Degradation of Thermosets, Polymer Degradation \& Stability, 74: 25-32.

[14] Hall, W.J., Miskolczi, N., Onwudili, J., Williams, P.T. (2008). Thermal Processing of Toxic Flame-Retarded Polymers Using a Waste Fluidized Catalytic Cracker (FCC) Catalyst, Energy \& Fuels, 22: 1691-1697.

[15] Quan, C., Li, A., Gao, N., Dan, Z. (2010). Characterization of Products Recycling From PCBs Waste Pyrolysis, Journal of Analytical and Applied Pyrolysis, 89: 102-106. 
[16] Moltó, J., Egea, S., Conesa, J.A., Font, R. (2011). Thermal Decomposition of Electronic Wastes: Mobile Phone Case and Other Parts, Waste Management, 31: 2546-2552.

[17] Chen, K.S., Chen, H.C., Wu, C.H., Chou, Y.M. (1999). Kinetics of Thermal and Oxidative Decomposition of Printed Circuit Boards, Journal of Environmental Engineering, 125: 277 283.

[18] Liou, T.H. (2004). Kinetics Study of Decomposition of Electric Packaging Material, Chemical Engineering Journal, 98: 39-51.

[19] Barotini, F., Cozzani, V. (2006). Formation of Hydrogen Bromide and Organobrominated Compounds in the Thermal Degradation of Electronic Boards. Journal of Analytical and Applied Pyrolysis, 77: 41-55.

[20] Friedman, H.L. (1965). Kinetics of Thermal Degradation of Char-Forming Plastics from Thermogravimetry - Application to a Phenolic Plastic, Journal of Polymer Science, Part C: Polymer Symposium, 6: 183-195.
[21] Li, J., Duan, H., Yu, K., Liu, L., Wang, S. (2010). Characteristic of Low-Temperature Pyrolysis of Printed Circuit Boards Subjected to Various Atmosphere, Resources, Conservation and Recycling, 54: 810-815.

[22] Guan, J., Li, Y.S., Lu, M.X. (2008). Product Characterization of Waste Printed Circuit Board by Pyrolysis Journal of Analytical and Applied Pyrolysis, 83: 185-189.

[23] Ni, M., Xiao, H., Chi, Y., Yan, J., Buekens, A., Jin, Y., Lu, S. (2012). Combustion and Inorganic Bromine Emission of Waste Printed Circuit Boards in a High Temperature Furnace, Waste Management, 32: 568-574.

[24] Buekens, A.G., Huang, H. (1998). Catalytic Plastics Cracking for Recovery of GasolineRange Hydrocarbons from Municipal Plastic Wastes, Resources, Conservation and Recycling, 23: 163-181. 